\title{
Formation of polypyrrole with dexamethasone as a dopant: Its cation and anion exchange properties
}

\author{
Eimear M. Ryan, Carmel B. Breslin* \\ Department of Chemistry, Maynooth University, Maynooth, Co. Kildare, Ireland
}

\section{A R T I C L E I N F O}

\section{Keywords:}

Polypyrrole

Dexamethasone

Electropolymerisation

Sodium accumulation

Mixed ion exchange

\begin{abstract}
A B S T R A C T
There is considerable interest in dexamethasone, a synthetic glucocorticosteroid drug, and a number of reports detailing the controlled release of dexamethasone from polypyrrole have been published. However, polypyrroledoped with dexamethasone is poorly characterised. In this study, polypyrrole doped with dexamethasone was formed at relatively low applied potentials of $0.70 \mathrm{~V}$ or $0.80 \mathrm{~V}$ vs SCE by carrying out the electropolymerisation on an initial pre-layer of polypyrrole. These polymers displayed electroactive behaviour with a dexamethasone doping level of $0.30 \pm 0.03$ and using impedance measurements the charge-transfer resistance was computed as $400 \Omega$. Mixed ion transport was observed. In addition to the release of dexamethasone, hydrated sodium cations were incorporated to maintain charge neutrality on reduction of the polymer. Approximately $200 \mu \mathrm{g} \mathrm{cm}^{-2}$ of dexamethasone was released following $60 \mathrm{~min}$ on reduction of the polymer at $-0.90 \mathrm{~V}$ vs SCE. It was possible to re-use the polymer to release the drug by repeated oxidation and reduction steps, where dexamethasone was incorporated during oxidation and released on reduction. During these events, sodium was accumulated within the polymer matrix and this high salt content accompanied with swelling and de-swelling events gave rise to the development of cracks in the polymer matrix.
\end{abstract}

\section{Introduction}

In recent years there has been considerable interest in conducting polymers as they possess a range of interesting properties and potential applications. Furthermore, they are easily formed and fabricated using electropolymerisation with a suitable dopant or by chemical polymerisation using a dopant and an oxidising agent. In particular, polypyrrole has been identified as a biomaterial with applications in tissue engineering, as biosensors and in drug delivery [1,2]. In terms of drug delivery, polypyrrole has been used to deliver anionic, cationic and neutral drug molecules [2-13]. The release of the drug molecule is achieved by electrochemically switching the polymer between its reduced and oxidised states. For anionic drugs, the drug molecule is incorporated as a dopant during the electropolymerisation of the monomer and it is then released on reduction of the polymer. Large immobile dopants are used to bind cationic drugs within the polymer matrix. In this case, the cationic drug is released on oxidation of the polymer. Dexamethasone is one drug molecule that has received a lot of interest [9-13]. This is no surprise, as it is a synthetic glucocorticosteroid and is used in several treatments including the reduction of inflammation [14]. The prodrug, dexamethasone 21-phosphate disodium salt, is anionic and it can be incorporated as an anionic dopant within the polymer and released on reduction of the polymer film.

However, dexamethasone is large and its solubility in aqueous solutions is relatively low, limiting the concentration that can be used during the electropolymerisation of pyrrole. As a result, relatively high applied potentials or high applied current densities are normally used to promote the growth of the dexamethasone doped polypyrrole. For example, Seyfoddin et al. [12] used an applied current density of $2 \mathrm{~mA} \mathrm{~cm}^{-2}$, while Zhang et al. [13] used current densities between 0.5 and $1.5 \mathrm{~mA} \mathrm{~cm}^{-2}$. Sirivisoot et al. [15] used cyclic voltammetry and cycled the potential to $1.1 \mathrm{~V}$ vs $\mathrm{Ag} / \mathrm{AgCl}$ to form the polymer, while Wadhwa et al. [16] formed the polymer at $1.8 \mathrm{~V}$ and subsequently released the dexamethasone by cycling the polymer between $-0.80 \mathrm{~V}$ and $1.4 \mathrm{~V}$ vs SCE. Although many of these conditions will give rise to more open and porous polymers, that are capable of delivering higher amounts of drugs, they are also likely to give rise to some degree of over-oxidation of the polypyrrole and as this is an irreversible reaction, it will limit the redox switching of the polymer. Furthermore, the focus of these publications is on the release of dexamethasone from the polymer matrix and little attention is devoted to the properties of the PPyDex polymer system.

The aim of this study is to gain information on the properties of PPyDex, including its conducting properties, cation and anion exchange

\footnotetext{
* Corresponding author.

E-mail address: Carmel.Breslin@mu.ie (C.B. Breslin).
} 
properties, and doping levels. In order to study these electrochemical properties, the PPyDex is formed under conditions that minimise the over-oxidation of the polymer matrix and the influence of these electropolymerisation conditions on the release of dexamethasone is briefly described.

\section{Experimental method}

The chemicals used throughout this study were purchased from Sigma-Aldrich (Analar grade reagents). Pyrrole was vacuum-distilled and stored in the dark at $-20^{\circ} \mathrm{C}$ prior to use. A standard three electrode cell was used in all experiments. A high surface area platinum wire served as the counter electrode and a saturated calomel (SCE) electrode was used as the reference electrode. A platinum disc electrode $(99.99 \%$ purity) with a surface area of $0.125 \mathrm{~cm}^{2}$ was employed as the working electrode (the surface area of the platinum substrate, and not the polymer, was used to express the release in $\mu \mathrm{g} \mathrm{cm}^{-2}$ ). The platinum electrode was fabricated by embedding a platinum rod in a Teflon holder, which was filled with epoxy resin and a copper wire was threaded into the base of the metal sample for electrical contact. The exposed surface was polished to a mirror finish using successively smaller sizes of diamond paste to a final size of $1 \mu \mathrm{m}$ on a microcloth (Buehler). The surface of the platinum electrode was then rinsed with distilled water, cleaned in an ultrasonic bath to remove any polishing residues and finally dried in a stream of air.

Cyclic voltammetry and potentiostatic current-time plots were carried out using a Solartron (Model SI 1287) potentiostat, while impedance measurements were performed with a Solartron frequency response analyser (Model SI 1255) in conjunction with an electrochemical interface (Solarton Model SI 1287). The EQCM experiments were carried out on a CHi440 EQCM system. The polymers were deposited onto polished Au quartz crystal electrodes (Cambria Scientific) with an exposed surface area of $0.203 \mathrm{~cm}^{2}$. The electrochemical cell consisted of a specially made Teflon holder in which the crystal was placed between two o-rings, a platinum wire counter and a custommade $\mathrm{Ag} \mid \mathrm{AgCl}$ reference electrode. The Sauerbrey equation, Eq. (1), was used to convert the oscillation frequency to the mass at the crystal. In this equation, $\Delta f$ represents the observed frequency change, $C_{\mathrm{f}}$ is the sensitivity of the crystal, which was found experimentally to be 7.9897 $\times 10^{8} \mathrm{~Hz} \mathrm{~cm}^{2} \mathrm{~g}^{-1}$, and $\Delta m$ represents the mass change. Thin polymer films were deposited to minimise viscoelastic effects, as this analysis is only valid for thin, uniform and rigid films on the crystal [17].

$\Delta m=-\frac{A \sqrt{\left(\rho_{q} \mu_{q}\right)}}{2 f_{o}^{2}} \Delta f=-\frac{1}{C_{f}} \Delta f$

The surface morphology of the polymer samples was obtained using a Hitachi SEM. The samples were sputter coated with gold using an Emitech K550x gold sputter coater prior to analysis.

The release of dexamethasone from the polypyrrole matrix was monitored using UV-visible spectroscopy (Cary 50 UV-visible spectrometer). Prior to the release experiments, the polymer was thoroughly washed in water, then immersed in distilled water and polarised at $0.50 \mathrm{~V}$ vs SCE for a $15 \mathrm{~min}$ period. The solution was stirred continuously throughout this period to aid diffusion of dexamethasone that was trapped within the polymer matrix. All release studies were repeated three times and the standard error was calculated and is represented as error bars on the release plots.

\section{Results and discussion}

The structure of dexamethasone is shown in Fig. 1, as the dexamethasone 21-phosphate disodium salt. The presence of the phosphate group on the dexamethasone steroid ring structure imparts a negative charge to the drug, making it suitable for incorporation as a dopant in polypyrrole. Although this salt is a divalent anion at $\mathrm{pH} 8.0, \mathrm{Dex}-\mathrm{PO}_{3}{ }^{2-}$

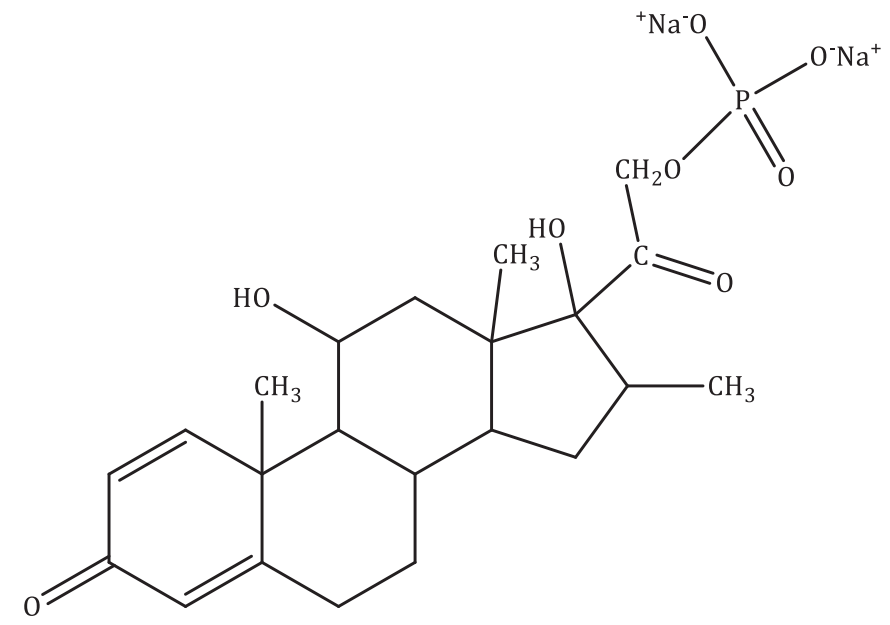

Fig. 1. Chemical structure of dexamethasone (shown as the sodium salt).

$\left(\mathrm{Dex}^{2-}\right)$ which is the natural $\mathrm{pH}$ of the solution when dexamethasone is dissolved, the $\mathrm{pKa}$ values of approximately 1.18 and 7.20 , will give rise to the formation of Dex- $\mathrm{HPO}_{3}{ }^{-}\left(\mathrm{Dex}^{-}\right)$, as the solution becomes acidified during the electropolymerisation process. This will give rise to a monovalent anion, $\mathrm{Dex}^{-}$, as the dopant. Although dexamethasone is a large dopant with a molecular weight of $470 \mathrm{~g} \mathrm{~mol}^{-1}$ (for $\mathrm{Dex}^{2-}$ ) it has been successfully incorporated into polypyrrole. However, as outlined earlier, high applied potentials $[15,16]$ or galvanostatic conditions at relatively high currents [12,13] are normally used. These approaches are likely to give rise to some over-oxidation of the polypyrrole matrix, reducing its redox activity.

\subsection{Electropolymerisation and formation of PPyDex}

In an attempt to form the polypyrrole film at lower applied potentials, the electropolymerisation of pyrrole in $0.05 \mathrm{~mol} \mathrm{dm}^{-3}$ Dex and $0.2 \mathrm{~mol} \mathrm{dm}^{-3}$ pyrrole at applied potentials between $0.70 \mathrm{~V}$ and $0.90 \mathrm{~V}$ vs SCE was studied. Although some polymer was nucleated and formed at the lower potentials, the current increased slowly over the timeframe of the experiment, and only patches of the polymer was observed at the electrode. This inefficient and low rate of electropolymerisation may be connected to the large size of dexamethasone and its large ring structure with poor flexibility, with no rotation of the molecule possible within this ring structure. Furthermore, the $\mathrm{pH}$ of the dexamethasonecontaining solution, is relatively high at 8.2. It is well known that the rate of electropolymerisation decreases as the $\mathrm{pH}$ is increased and it is difficult to electropolymerise pyrrole at $\mathrm{pH}$ values higher than 8.0 $[18,19]$. When the applied potential was increased to $0.90 \mathrm{~V}$ vs SCE, the polymer, PPyDex, formed rapidly. A representative current-time plot is shown in Fig. 2. There is a rapid increase in the current over the initial $180 \mathrm{~s}$, then a steady state current, or plateau, is observed, indicating a constant rate of electropolymerisation. However, these high rates of electropolymerisation gave rise to poor reproducibility and different amounts of polymer were deposited. In order to control the rate of electropolymerisation and maintain the conducting and redox activity of the polymer, a two-step approach was used. This involved the formation of the polymer at an initially high potential of $0.90 \mathrm{~V}$ vs SCE to nucleate the polymer at the surface, followed by a slower and more controlled rate of electropolymerisation. In Fig. 3, data are shown, as charge-time plots, for the formation of PPyDex at lower applied potentials at PPyDex or PPyCl modified electrodes. In Fig. 3(a) a potential of $0.90 \mathrm{~V}$ vs SCE was applied until a charge of $0.8 \mathrm{C} \mathrm{cm}^{-2}$ was reached and then the remaining polymer growth was carried out at $0.80 \mathrm{~V}$ vs SCE until a charge of $2.0 \mathrm{C} \mathrm{cm}^{-2}$, giving a total charge of $2.8 \mathrm{C} \mathrm{cm}^{-2}$. For the initial step at $0.90 \mathrm{~V}$ vs SCE, the slopes of the charge-time plots (linear region) varied from $3.3 \times 10^{-3}$ to $4.8 \times 10^{-3} \mathrm{C} \mathrm{cm}^{-2} \mathrm{~s}^{-1}$ while 


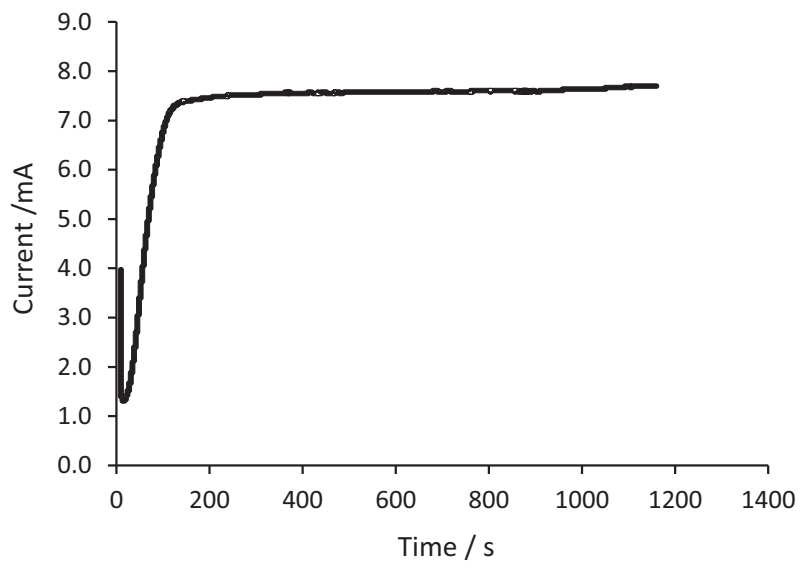

Fig. 2. Current-time plot recorded during the deposition of PPyDex at $0.90 \mathrm{~V}$ vs SCE in $0.05 \mathrm{~mol} \mathrm{dm}^{-3}$ Dex and $0.20 \mathrm{~mol} \mathrm{dm}^{-3}$ pyrrole.

the slopes ranged from $3.9 \times 10^{-3}$ to $4.1 \times 10^{-3} \mathrm{C} \mathrm{cm}^{-2} \mathrm{~s}^{-1}$ in the second step. These data show that once the initial deposition of PPyDex is achieved, the rate of electropolymerisation of pyrrole at $0.80 \mathrm{~V}$ vs SCE is considerably more reproducible and occurs at a rate which is similar to that observed initially at $0.90 \mathrm{~V}$ vs SCE. For the data shown in Fig. 3(b), the PPyCl film was formed at $0.60 \mathrm{~V}$ vs SCE to reach a charge of $0.16 \mathrm{C} \mathrm{cm}^{-2}$, and then the PPyDex film was formed at $0.80 \mathrm{~V}$ or $0.70 \mathrm{~V}$ until a total charge of $2.8 \mathrm{C} \mathrm{cm}^{-2}$ was achieved. Again, it is clearly evident that PPyDex can be formed at much lower applied potentials once an initial layer of polypyrrole is deposited at the surface. The thickness of the polymers was estimated as $5.8 \mu \mathrm{m}$ using Faraday's Law, Eq. (2), where $M$ is the molar mass of pyrrole, q is the charge, A is the surface area of the electrode, $z$ is the number of electrons transferred, $F$ is the Faraday constant and $\rho$ is the density of polypyrrole, taken as $1.5 \mathrm{~g} \mathrm{~cm}^{-3}$. However, as the dopant is large, the thickness will be somewhat higher than this theoretical estimate.

$x=\frac{q M}{\rho A z F}$

\subsection{Doping level of PPyDex}

EQCM was used to study the initial steps in the electropolymerisation and to obtain information on the doping level of the PPyDex film. The PPyDex was grown to a charge of $3.5 \times 10^{-2} \mathrm{C}$ by applying a constant potential of $0.90 \mathrm{~V}$ vs $\mathrm{Ag} / \mathrm{AgCl}$. In Fig. 4, the frequency-charge and mass-charge plots are shown. It can be seen that the mass increases and the frequency decreases sharply once a charge of $1.5 \times 10^{-2} \mathrm{C}$ is reached. This is very different to that observed on forming $\mathrm{PPyCl}$, shown in the inset in Fig. 4. Once this charge is reached, the mass-tocharge ratio is approximately $1.2 \times 10^{-3} \mathrm{~g} \mathrm{C}^{-1}$, while a much lower ratio of $3.6 \times 10^{-4} \mathrm{~g} \mathrm{C}^{-1}$ is obtained during the initial stage of deposition. This may be related to soluble polymer oligomers that do not deposit onto the electrode, or possibly the adsorption of dexamethasone at the electrode surface. Indeed, as evident from the cyclic voltammograms shown in Fig. 5, the presence of dexamethasone gives rise to a reduction in the peaks associated with hydrogen ion adsorption and there is a considerable shift in the peak potential for the reduction of platinum oxide/hydroxide, from approximately $-0.50 \mathrm{~V}$ to $-0.80 \mathrm{~V}$ vs SCE. This is consistent with the adsorption of dexamethasone, which may initially inhibit the electropolymerisation process.

The EQCM measurements were used with Eq. (3), a derivation of Faraday's law, to estimate the doping levels. In these equations, $M$ is the total mass of the deposited polymer, $Q$ is the charge reached, $M_{m}$ is the mass of the monomer, $M_{\text {dop }}$ is the mass of the dopant, $x$ is the doping level $(\mathrm{x} \leq 0.33)$ and $F$ is Faraday's constant. However, this equation does not take into account solvent participation, or the adsorption of dexamethasone, and assumes a $100 \%$ efficiency in the electropolymerisation of the monomer. Using the slope of the linear masscharge data, for $\mathrm{PPyCl}$ (shown in the inset), the doping level was calculated as 0.33 , in good agreement with several previous studies [20,21].

$\frac{M}{Q}=\frac{\left(M_{m}\right)+\left(M_{d o p)}\right) x}{(2+x) F}$

However, the mass-charge data for PPyDex does not have a simple linear relationship. The initial mass-charge slope of $3.6 \times 10^{-4} \mathrm{~g} \mathrm{C}^{-1}$ indicates inefficient electropolymerisation and the mass-charge slope at the later times is more representative of the bulk polymer deposition. The initial doping level was estimated as $0.025 \pm 0.005$, while the doping level associated with the second step was considerably higher at $0.30 \pm 0.03$. This results in a doping level of about 0.30 , once the initial growth period has elapsed.

\subsection{Conducting and mixed ion exchange properties}

The redox properties of PPyDex were examined using cyclic cyclic voltammetry coupled with EQCM. These data are shown in Fig. 6 and were recorded in an acidified $\mathrm{pH} 3.0,0.1 \mathrm{~mol} \mathrm{dm}^{-3} \mathrm{NaCl}$ solution. During the reduction scan, an increase in mass occurs, corresponding to the insertion of sodium cations, or sodium cations with water molecules. Although there may be some dopant anions released from the polymer during this period, the net mass change shows high amounts of sodium intake. This increase in mass begins at approximately $0.0 \mathrm{~V}$ vs $\mathrm{Ag} / \mathrm{AgCl}$, and continues to increase, reaching a maximum rate at $-0.40 \mathrm{~V}$ vs $\mathrm{Ag} / \mathrm{AgCl}$, close to the potentials where the reduction peak is observed in the voltammogram. During the reverse cycle, the mass decreases corresponding to the ejection of the cations. A further increase in mass is seen between approximately $0.40 \mathrm{~V}$ and $0.80 \mathrm{~V}$ vs Ag/ $\mathrm{AgCl}$ and this is connected to the uptake of chloride anions from the supporting electrolyte. These data show that the polymer displays mixed ion exchange behaviour. In addition to the uptake of $\mathrm{Na}^{+}$and the release of $\mathrm{Cl}^{-}$or $\mathrm{Dex}^{-}$from the polymer film, solvent/water molecules are also transferred. It is also clear that the rate of $\mathrm{Na}^{+}$uptake is higher that its rate of release, as evident from the slopes of the mass data, Fig. 6. This may indicate the incorporation of a large amount of water with the $\mathrm{Na}^{+}$. Alternatively, it may point to a slower release of $\mathrm{Na}^{+}$due to electrostatic interactions with the anionic dexamethasone,
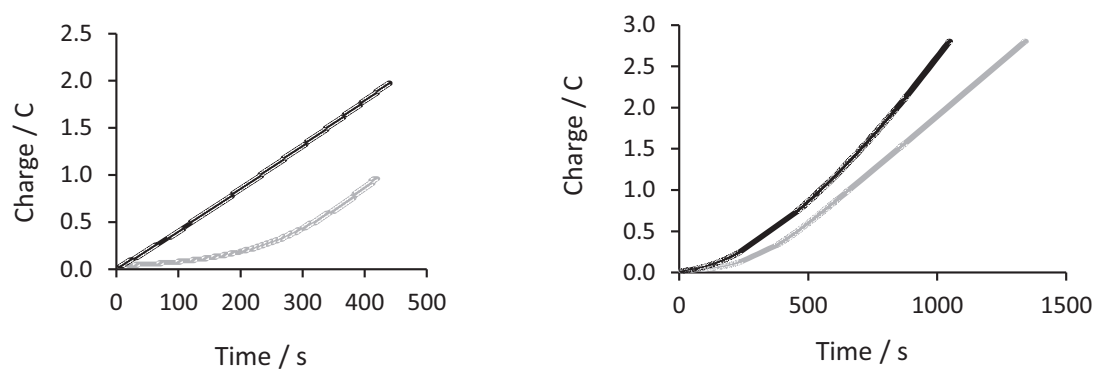

Fig. 3. Charge-time plots for the formation of PPyDex in $0.05 \mathrm{~mol} \mathrm{dm}^{-3} \mathrm{NaDex}$ and $0.20 \mathrm{~mol} \mathrm{dm}^{-3}$ pyrrole (left) at a constant potential of $0.90 \mathrm{~V}$ vs SCE on platinum and $0.80 \mathrm{~V}$ vs SCE on a PPyDex film and (right) formation of PPyDex on a film of PPyCl at $0.80 \mathrm{~V}$ vs SCE and at $0.70 \mathrm{~V}$ vs SCE. 

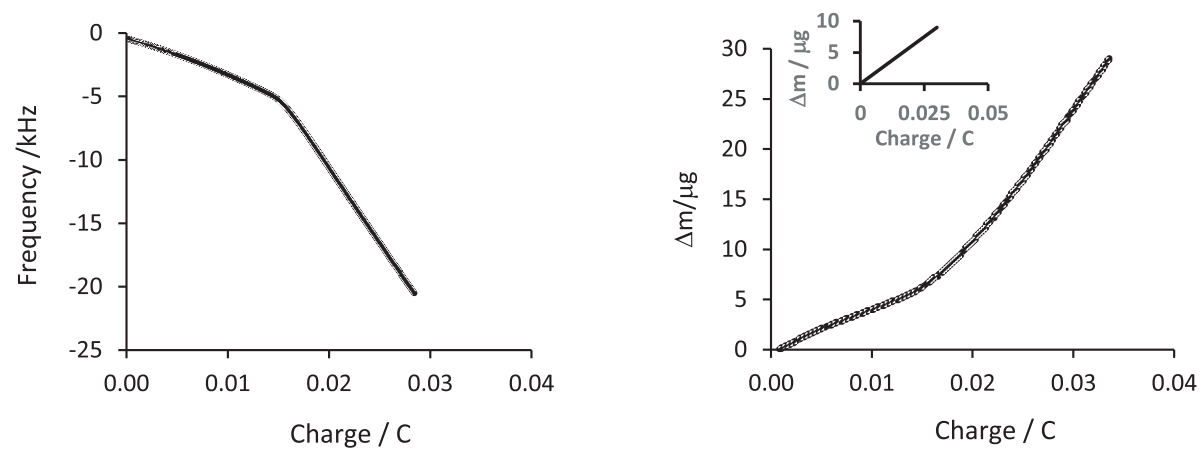

Fig. 4. Frequency-charge plots and mass-charge plots for the deposition of PPyDex in the presence of $0.05 \mathrm{~mol} \mathrm{dm}^{-3} \mathrm{NaDex}$ and $0.20 \mathrm{~mol} \mathrm{dm}{ }^{-3}$ pyrrole. Inset shows the charge-time plots for $\mathrm{PPyCl}$.

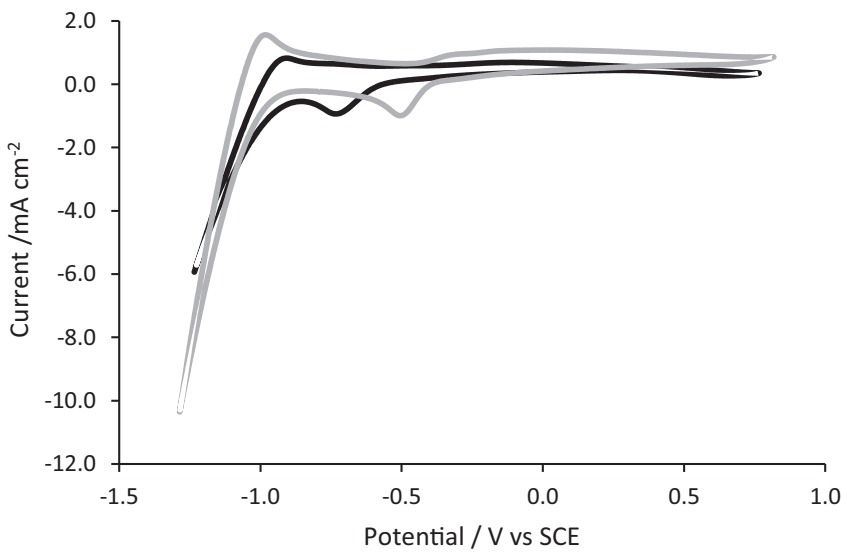

Fig. 5. Cyclic voltammograms, 20th cycle, of Pt in $-0.05 \mathrm{~mol} \mathrm{dm}^{-3}$ Dex and $0.10 \mathrm{~mol} \mathrm{dm}^{-3} \mathrm{NaCl}$ and in $-0.10 \mathrm{~mol} \mathrm{dm}^{-3} \mathrm{NaCl}(\mathrm{pH}=8.2)$ at a scan rate of $25 \mathrm{mV} \mathrm{s}^{-1}$.

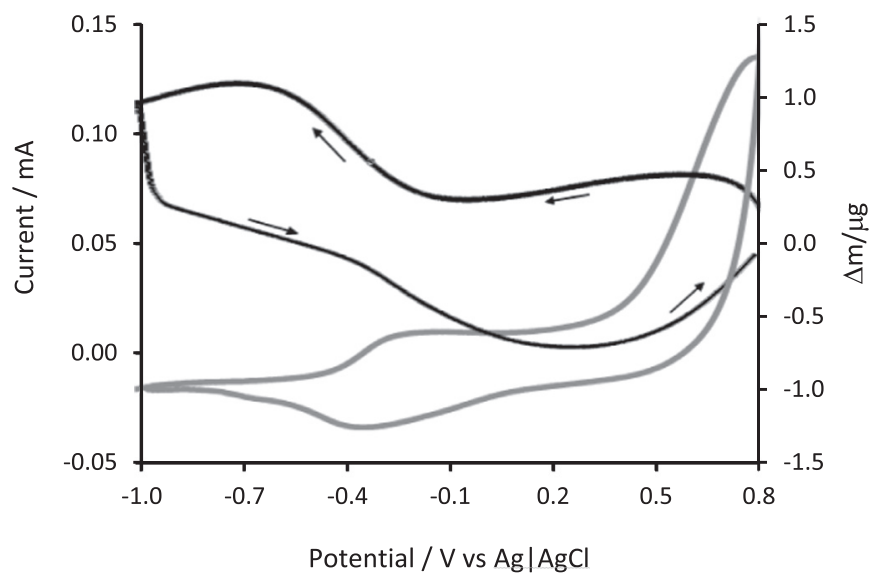

Fig. 6. Current coupled with mass change recorded for PPyDex in $0.10 \mathrm{~mol} \mathrm{dm}^{-3} \mathrm{NaCl}, \mathrm{pH} 3.0$ at a scan rate of $4 \mathrm{mV} \mathrm{s}^{-1}$.

Dex ${ }^{-}$, within the polymer matrix or a complex relationship between the release of $\mathrm{Na}^{+}$and the uptake of $\mathrm{Cl}^{-}$. This indicates that dexamethasone behaves like a medium-to-large sized anion and displays mixed ion exchange behaviour. It is well known that the exchange properties of polypyrrole depend on the size, type and valence of the dopant and when small dopants, such as chloride, are used, the charge neutrality on reduction of the polymer is achieved by the expulsion of the anionic dopant $[22,23]$. When dopants such as polystyrenesulfonate or dodecylbenzenesulfonate, are incorporated into polypyrrole, then the polymer acts like a cation exchanger and cations are transferred from the solution to the polymer matrix to maintain charge balance on reduction as the large dopants are immobile and not released [24].

It is also evident from Fig. 6 that PPyDex is conducting and these conducting properties were further explored using electrochemical impedance data. These data were recorded as a function of time over $8 \mathrm{~h}$ in a $0.1 \mathrm{~mol} \mathrm{dm}^{-3} \mathrm{NaCl}$ solution. Representative data recorded at the open-circuit potential $(0.24 \mathrm{~V}$ vs SCE) and at $-0.90 \mathrm{~V}$ vs SCE are shown as Bode plots in Fig. 7. These plots represent a partially oxidised and reduced polymer film. It is clear that the impedance changes on reduction of the polymer, with the impedance increasing. Furthermore, the impedance changes from a two- to a one-time constant model on reduction. The open-circuit potential data were fitted to the equivalent circuit shown in Fig. 7 (b), while data recorded at $-0.90 \mathrm{~V}$ vs SCE were fitted to the circuit depicted in Fig. 7(c). In these circuits, R1 corresponds to the solution resistance, R2 represents the charge-transfer resistance, while CPE1 and CPE2 are equivalent to the capacitance of the polymer and diffusional processes. The computed values of the circuit elements are summarised in Table 1 for the reduced and partially oxidised polymer films. The charge-transfer resistance at the open-circuit-potential was found to increase from an initial value of $370 \Omega$ to $400 \Omega$ (area of substrate is $0.125 \mathrm{~cm}^{2}$ ) which was calculated following $300 \mathrm{~min}$. The resistance then remained constant indicating good stability, conductivity and steady-state conditions. This relatively low resistance is consistent with conducting properties. On reduction of the polymer film, the resistance increased to $12 \mathrm{k} \Omega$, due to the reduction of the polymer. However, this resistance is not particularly high and it is consistent with the mixed ion exchange properties where the conducting polymer, $\mathrm{PPy}^{+} \mathrm{Dex}^{-}$, is converted to a mixture of $\mathrm{PPy}^{\circ}$ and $\mathrm{PPy}^{\circ} \mathrm{Dex}^{-} \mathrm{Na}^{+}$. As a constant phase element was used to model the capacitance of the partially oxidised polymer film, it is difficult to accurately estimate the capacitance as the exponent was 0.70 and too far removed from the ideal value of 1.0 expected for a capacitor. This is also evident in Fig. 7(a), where the phase angle deviates considerably from the $90^{\circ}$ expected for a capacitor. However, the exponent of the CPE was 0.5 for the reduced polymer representing a clear diffusional process and this may be related to the ingress of $\mathrm{Na}^{+}$cations as the polymer is reduced.

\subsection{Release of Dex from PPyDex and cation exchange}

As the published papers describing PPyDex have focussed on the release of dexamethasone from the polymer matrix, the release of dexamethasone was studied from these conducting polymer films. Shown in Fig. 8, are the dexamethasone release studies obtained on reduction of the polymer at $-0.90 \mathrm{~V}$ vs SCE for PPyDex formed at $0.90 \mathrm{~V}$ vs SCE, and formed at the lower potential of $0.80 \mathrm{~V}$ vs SCE using a two-step process with electropolymerisation of the second layer at $\mathrm{PPyDex}$ or PPyCl. The three polymer systems were deposited to the same charge of $2.8 \mathrm{C} \mathrm{cm}^{-2}$. It is clear from these data, that the amount of dexamethasone released depends on how the polymer was formed. 
(a)
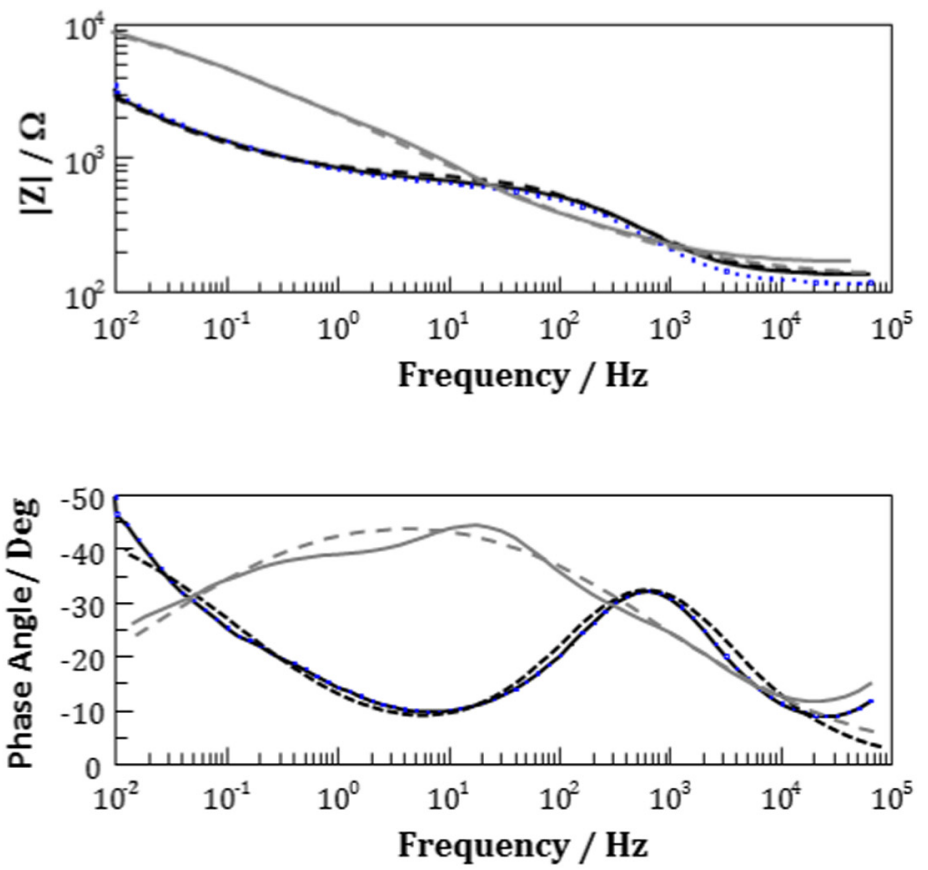

Fig. 7. (a) Impedance data recorded at $-0.90 \mathrm{~V}$ vs SCE $(-)$ and at OCP (-) for PPyDex in $0.1 \mathrm{~mol} \mathrm{dm}^{-3} \mathrm{NaCl}$. Experimental data $(-)$ and simulated data (- - - - -) generated using the equivalent circuits, (b) equivalent circuit at OCP and (c) equivalent circuit at $-0.90 \mathrm{~V}$ vs SCE.

(b)

(c)

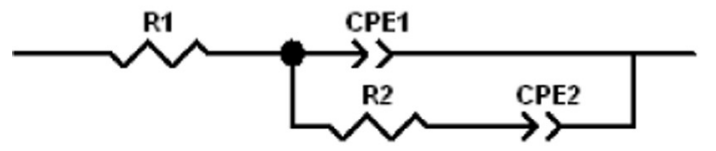

Table 1

Circuit elements obtained on fitting the impedance data obtained after $8 \mathrm{~h}$ at OCP $(0.24 \mathrm{~V}$ vs SCE) and at $-0.90 \mathrm{~V}$ vs SCE.

\begin{tabular}{llll}
\hline Circuit parameter & \% Error & Potential/V vs SCE \\
\cline { 3 - 4 } & & OCP & $-0.90 \mathrm{~V}$ \\
\hline R2 & 1.5 & $400 \Omega$ & $12,312 \Omega$ \\
CPE1 & 1.2 & $3.5 \times 10^{-4} \Omega^{-1} \mathrm{~s}^{-0.7}$ & $1.3 \times 10^{-4} \Omega^{-1} \mathrm{~s}^{-0.49}$ \\
CPE1 (exponent) & 0.5 & 0.70 & 0.49 \\
CPE2 & 1.7 & $5.5 \times 10^{-3} \Omega^{-1} \mathrm{~s}^{-0.8}$ & - \\
CPE2 (exponent) & 0.3 & 0.80 & - \\
\hline
\end{tabular}

The highest release, corresponding to approximately $200 \mu \mathrm{g} \mathrm{cm}^{-2}$ after 60 min, was achieved with the PPyDex formed using two steps, with the PPyDex deposited at $0.80 \mathrm{~V}$ vs SCE at the initial PPyDex layer. The amount of dexamethasone released was reduced to $155 \mu \mathrm{g} \mathrm{cm}^{-2}$ when the PPyDex was formed in a single step at $0.90 \mathrm{~V}$ vs SCE, and although this will lead to a more porous and open polymer structure with a higher surface area, it appears that the polymer formed at these higher potentials is susceptible to over-oxidation. As the concentration of dexamethasone is lower in the PPyDex film deposited at the PPyCl layer, a lower amount was released, showing that the concentration of dexamethasone is an important parameter even close to the electrode surface.

The more conducting PPyDex films generated using the two step approach (formation at $0.90 \mathrm{~V}$ and $0.80 \mathrm{~V}$ vs SCE in the presence of dexamethasone) were studied to obtain further information on the release of the drug. The influence of the applied potential on the release is summarised in Fig. 9. In general, higher amounts are released as the

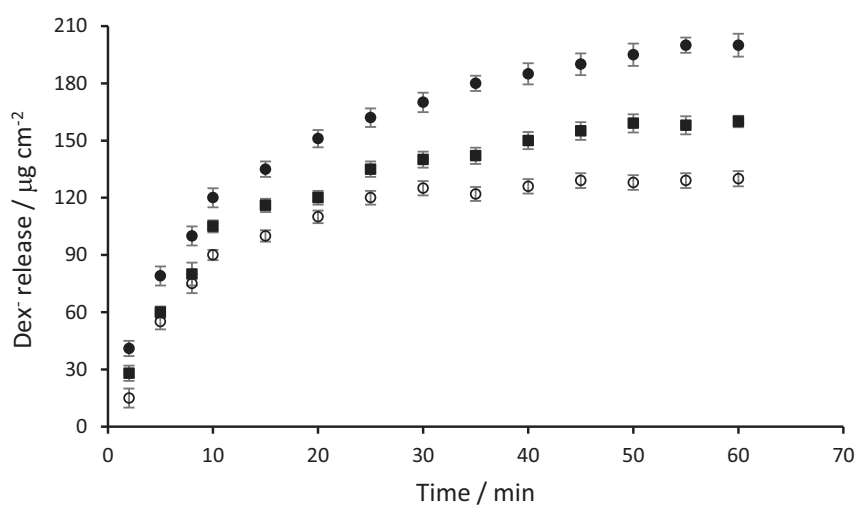

Fig. 8. The amount of Dex measured as a function of time on reducing the polymer films at $-0.90 \mathrm{~V}$ vs SCE for - PPyDex formed at $0.80 \mathrm{~V}$ vs SCE at a PPyDex film, for $\bigcirc$ PPyDex formed at $0.80 \mathrm{~V}$ at a PPyCl film and for $\square$ PPyDex formed at $0.90 \mathrm{~V}$ vs SCE $(n=3)$.

applied potential is lowered and the polymer is reduced with more efficient release achieved at $-0.90 \mathrm{~V}$ vs SCE. This is in good agreement with the data presented in Fig. 6, where the reduction wave is seen at approximately $-0.40 \mathrm{~V}$ vs $\mathrm{Ag} \mid \mathrm{AgCl}$. The relatively poor release of dexamethasone observed at $-1.0 \mathrm{~V}$ vs SCE is probably due to the competing hydrogen evolution reaction. In addition to consuming charge, this reaction may also alter the interface between the electrode and the polymer interface, or lead to local delamination of the polymer, preventing or inhibiting the reduction of the polymer. However, it is evident from Fig. 6 that in addition to the release of dexamethasone, 


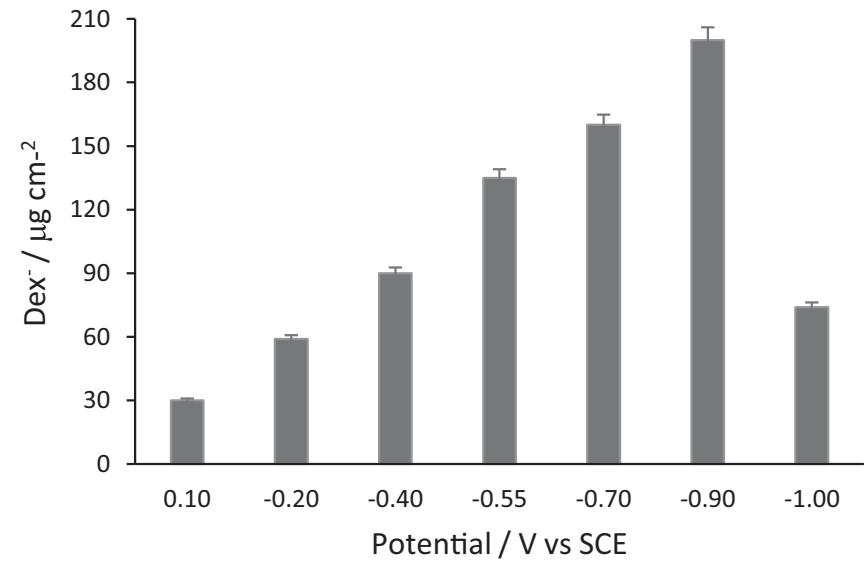

Fig. 9. Amount of Dex released following $60 \mathrm{~min}$ at various applied potentials $(n=3)$.

sodium cations from the solution enter the polymer matrix during this process. Furthermore, as the uptake of sodium begins at approximately $0.0 \mathrm{~V}$ vs $\mathrm{Ag} / \mathrm{AgCl}$, Fig. 6, there are no suitable applied potentials that can be used to release dexamethasone and prevent the incorporation of sodium into the polymer film.

The amount of dexamethasone available for release was estimated as $270 \pm 8 \mu \mathrm{g} \mathrm{cm}^{-2}$ by measuring the amount of dexamethasone released after $10 \mathrm{~h}$ at $-0.90 \mathrm{~V}$ vs SCE. As cations are injected on reduction of the polymer film not all the incorporated dexamethasone is released. Assuming that the doping level remains at 0.30 for the bulk polymer, the amount of dexamethasone incorporated within the polypyrrole films was estimated as $1.9 \mathrm{mg} \mathrm{cm}^{-2}$. Although the complete reduction and release of any drug or dopant is unlikely and the estimated uptake of $1.9 \mathrm{mg} \mathrm{cm}^{-2}$, which is based on EQCM data, does not take into account solvent participation, there is a significant difference between the quantities of dexamethasone incorporated and released. This is consistent with the incorporation of cations during the release of dexamethasone and as more cations are incorporated more of the dexamethasone remains within the polymer films.

The possibility of reusing the PPyDex films was studied by re-oxidising the reduced polymer film in the presence of $0.06 \mathrm{~mol} \mathrm{dm}^{-3}$ dexamethasone at $0.80 \mathrm{~V}$ vs SCE. Then the polymers were reduced at $-0.90 \mathrm{~V}$ vs SCE and the release of dexamethasone was followed. This was repeated several times and representative data are shown in Fig. 10. In this figure, the amount of dexamethasone released following a 60-min release period is shown as a function of the number of times the polymer was used and exposed to an oxidation and reduction event. There is a considerable reduction in the amount of dexamethasone released on comparing the first and second release experiments. This is expected as it is well known that there is a loss in the conductivity of polypyrrole when it is reduced for extended time periods [25]. However, unexpected results were obtained for the third and fourth release experiments, which show a gradual and significant increase in the amount of dexamethasone released. This indicates that the incorporation or release of dexamethasone becomes increasingly easier as the polymer is cycled between reduction and oxidation.

This may be related to the presence of sodium within the polymer matrix. During repeated reduction and oxidation of the polymer it is possible that higher amounts of sodium are accumulated within the polymer film and consequently to maintain charge neutrality more dexamethasone is transferred to the polymer. Latonen et al. [26] in studying the ion exchange behaviour of polypyrrole doped with large anions, suggested the formation of ion pairs, this electrostatic interaction between the cation and anion makes it more difficult to expel the cation on oxidation of the polymer. Indeed, there is evidence in Fig. 6, that the rate of the sodium cation expulsion is slower than its ingress. It is also possible that the formation of these ion pairs facilitate the uptake of higher concentrations of dexamethasone, as illustrated in Eq. (4). In this analysis the reduced polymer film is represented as containing some dexamethasone, $\mathrm{PPy}^{0} \cdot n \mathrm{Dex}^{-} \cdot \mathrm{nNa}^{+} \cdot \mathrm{bH}_{2} \mathrm{O}$. On oxidation, the sodium is released, but some remains, possibly forming an ion pair with the dexamethasone. On further oxidation, uptake of dexamethasone occurs due to the positively charged backbone, however additional dexamethasone is incorporated to neutralise the positively charged sodium cation, as illustrated in Eq. (4).

$\mathrm{PPy}^{0} . n \mathrm{Dex}^{-} \mathrm{nNa}^{+} \mathrm{b} \mathrm{H}_{2} \mathrm{O} \stackrel{-z e^{-}-x \mathrm{Na}^{+}-a \mathrm{H}_{2} \mathrm{O}}{\longrightarrow} \mathrm{PPy}^{x+} \cdot \mathrm{nDex}^{-} .(\mathrm{n}-\mathrm{x}) \mathrm{Na}^{+}$.

$$
(b-a) \mathrm{H}_{2} \mathrm{O}
$$

$\stackrel{-c e^{-}+(m+n-x) D e x^{-}}{\longrightarrow} \mathrm{PPy}^{(\mathrm{m}+\mathrm{n})+} .(n+m) \mathrm{Dex}^{-} .(\mathrm{n}-\mathrm{x}) \mathrm{Na}^{+} .(n-x) \operatorname{Dex}^{-}$.

(d) $\mathrm{H}_{2} \mathrm{O}$

As more sodium ions are incorporated, some of these ion pairs may become detached from the polymer backbone and during the subsequent release experiment, they may be released through a diffusion-
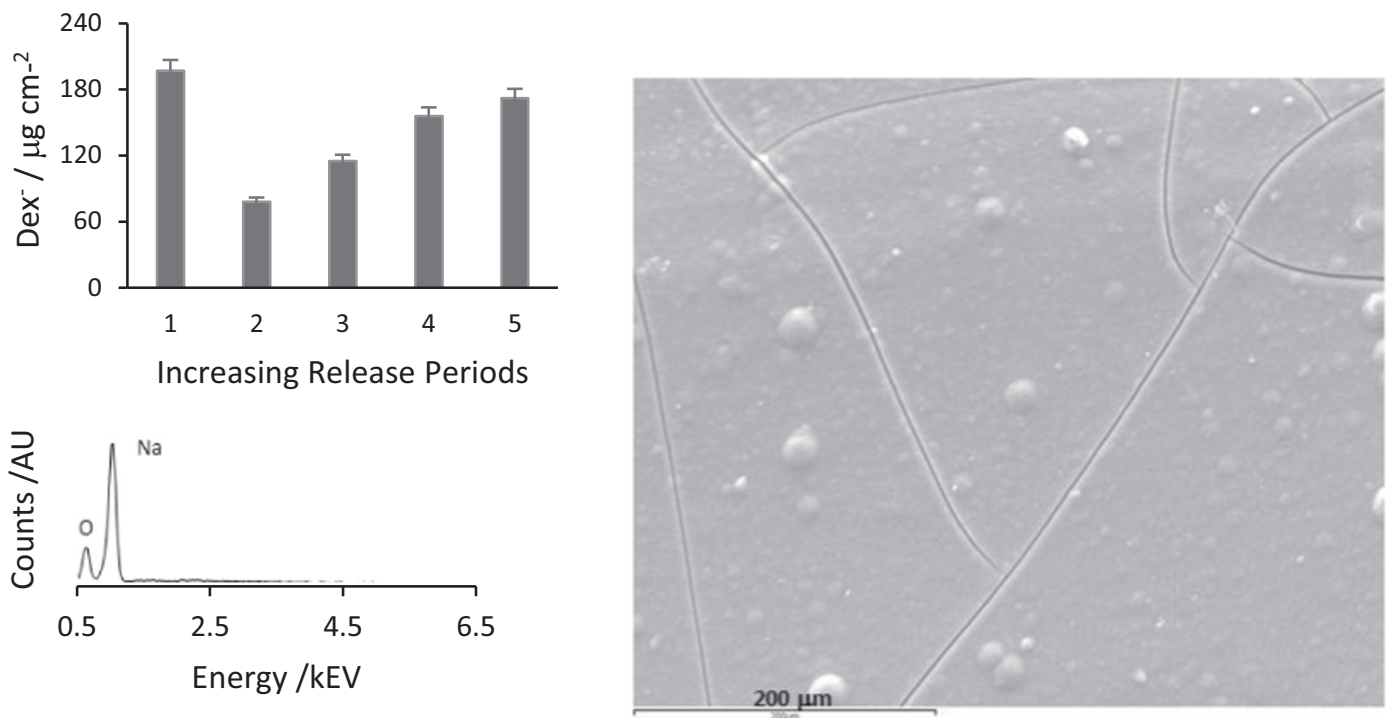

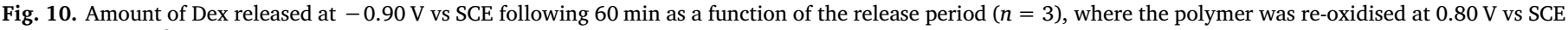
in $0.06 \mathrm{~mol} \mathrm{dm} \mathrm{m}^{-3}$ Dex between the release periods. SEM micrograph of PPyDex and the EDX spectrum following six repeated release periods. 
controlled process giving a further increase in the amount released. Even though the conductivity of the polymer film may be decreasing on repeated oxidation and reduction, and this would normally give rise to a reduction in the release of dexamethasone, the opposing effect becomes more significant arising from the cation exchange properties of the polymer, to give the trend seen in Fig. 10. This high uptake of dopants, ion pairs and accumulation of salt leads to swelling and deswelling of the polymer matrix and structural damage becomes evident. This is clearly seen in Fig. 10, where the surface of the PPyDex following repeated release and doping steps is shown. The micrograph indicates the presence of cracks caused by swelling and de-swelling events. Furthermore, the accompanying EDX spectrum shows evidence of sodium uptake. The oxygen signal is related to the presence of dexamethasone and possibly to the formation of carbonyl groups that arise from the over-oxidation of polypyrrole which may occur following these repeated oxidation steps.

\section{Conclusions}

Polypyrrole doped with dexamethasone was easily deposited onto a pre-layer of polypyrrole, $\mathrm{PPyCl}$ or PPyDex, at relatively low applied potentials of $0.70 \mathrm{~V}$ or $0.80 \mathrm{~V}$ vs SCE. The polymers were deposited to $2.8 \mathrm{C} \mathrm{cm}^{-2}$, to give relatively thick polymers, that had a low chargetransfer resistance of $400 \Omega\left(0.125 \mathrm{~cm}^{2} \mathrm{Pt}\right.$ surface area). Using EQCM, the doping level was calculated as $0.30 \pm 0.03$. The uptake of sodium was clearly observed for thin polymer films using EQCM. A higher amount of dexamethasone was released for the more conducting polymers formed at the lower applied potential, while the rate of release increased on the application of more electronegative potentials with the highest rate of release evident at $-0.90 \mathrm{~V}$ vs SCE. During repeated oxidation and reduction of the polymer film, an increasing amount of dexamethasone was released and this was explained in terms of the cation exchange properties of the polymer films. It appears that sodium is accumulated within the polymer matrix. While this gives higher release rates, the associated swelling and de-swelling of the polymer film leads to the development of structural damage and cracks within the polymer matrix. Although it is possible to release relatively high amounts of dexamethasone on reduction of polypyrrole, this system will also uptake cations from the release medium and this may limit its potential as a delivery system for dexamethasone.

\section{Acknowledgements}

The authors would like to acknowledge funding from the Irish Research Council for Science, Engineering and Technology (IRCSET) Ireland.

\section{References}

[1] G. Kaur, R. Adhikari, P. Cass, M. Brown, P. Gunatillake, Electrically conductive polymers and composites for biomedical applications, RSC Adv. 5 (47) (2015) 37553-37567.

[2] B. Zinger, L.L. Miller, Time release of chemicals from polypyrrole films, J. American
Chemical Society 106 (1984) 6861-6863.

[3] K. Kontturi, P. Pentti, G. Sundholm, Polypyrrole as a model membrane for drug delivery, J. Electroanal. Chem. 453 (1998) 231-238.

[4] L.L. Miller, X.Q. Zhou, Poly (N-methylpyrrolylium) poly (styrenesulfonate)-a conductive, electrically switchable cation exchanger that cathodically binds and anodically releases dopamine, Macromolecules 20 (1987) 1594-1597.

[5] M. Hepel, F. Mahdavi, Application of the electrochemical quartz crystal microbalance for electrochemically controlled binding and release of chlorpromazine from conductive polymer matrix, Microchem. J. 56 (1997) 54-64.

[6] D. Svirskis, M. Sharma, Y. Yu, S. Garg, Electrically switchable polypyrrole film for the tunable release of progesterone, Ther. Deliv. 4 (2013) 307-313.

[7] B. Massoumi, A. Entezami, Electrochemically-controlled binding and release of dexamethasone from conducting polymer bilayer films, J. Bioact. Compat. Polym. 17 (2002) 51-62.

[8] J.-M. Pernaut, J.R. Reynolds, Use of conducting electroactive polymers for drug delivery and sensing of bioactive molecules. A redox chemistry approach, J. Phys. Chem. B 104 (2000) 4080-4090.

[9] L. Leprince, A. Dogimont, D. Magnin, S. Demoustier-Champagne, Dexamethaasone electrically controlled release from polypyrrole-coated nanostructured electrodes, J. Mater. Sci. Mater. Med. 21 (2010) 925-930.

[10] I.A. Paun, M. Zamfirescu, C.R. Luculescu, A.M. Acasandrei, C.C. Mustaciosu, M. Mihailescu, Electrically-responsive microreservoires for controlled delivery of dexamethasone in bone tissue engineering, Appl. Surf. Sci. 392 (2017) 321-331.

[11] A. Ramtin, A. Seyfoddin, F.P. Coutinho, G.I.N. Waterhouse, I.D. Rupenthal, D. Svirskis, Cytotoxicity considerations and electrically tunable release of dexamethasone from polypyrrole for the treatment of back-of-eye condition, Drug Delivery and Translational Research 6 (2016) 793-799.

[12] A. Seyfoddin, A. Chan, W.-T. Chen, I.D. Rupenthal, G.I.N. Waterhouse, D. Svirskis, Electro-responsive macroporous polypyrrole scaffolds for triggered dexamethasone delivery, Eur. J. Pharm. Biopharm. 94 (2015) 419-426.

[13] B. Zhang, P.J. Molino, A.R. Harris, Z. Yue, S.E. Moulton, G.G. Wallace, Conductive and protein resistant polypyrrole films for dexamethasone delivery, J. Mater. Chem. B 4 (2016) 2570-2577.

[14] A. Grodzinsky, J. Alan, Y. Wang, S. Kakar, M.S. Vrahas, C.H. Evans, Intra-articular dexamethasone to inhibit the development of post-traumatic osteoarthritis, J. Orthop. Res. 35 (3) (2017) 406-411.

[15] S. Sirivisoot, R. Pareta, T.J. Webstar, Electrically-controlled drug release from nanostructured polypyrrole coated on titanium, Nanotechnology 22 (2011) 085101.

[16] R. Wadhwa, C.F. Lagenaure, X.T. Cui, Electrochemically controlled release of dexamethasone from conducting polymer polypyrrole coated electrode, J. Control. Release 110 (2006) 531-541.

[17] C.K. Baker, J.R. Reynolds, A quartz microbalance study of the electrosynthesis of polypyrrole, J. Electroanal. Chem. 251 (1988) 307-322.

[18] A.F. Diaz, J.I. Castillo, J.A. Logan, W.-Y. Lee, Electrochemistry of conducting polypyrrole films, J. Electroanal. Chem. 129 (1981) 115-132.

[19] S. Shimoda, E. Smela, The effect of $\mathrm{pH}$ on polymerization and volume change in PPyDBS, Electrochim. Acta 44 (1998) 219-238.

[20] G. Maia, R.M. Torresi, E.A. Ticianelli, F.C. Nart, Charge compensation dynamics in the redox process of polypyrrole modified electrodes, J. Phys. Chem. 100 (1996) 15910-15916.

[21] V. Syritski, A. Opik, O. Forsen, Ion transport investigations of polypyrrole doped with different anions by EQCM and CER techniques, Electrochim. Acta 48 (2003) 1409-1417.

[22] S. Bruckenstein, J. Chen, I. Jureviciute, A.R. Hillman, Ion and solvent transfers accompanying redox switching of polypyrrole films immersed in divalent anion solutions, Electrochim. Acta 54 (2009) 3516-3525.

[23] J.R. Reynolds, M. Pyo, Y.-J. Qui, Cation and anion transport during electrochemical switching of polypyrrole controlled by polymer ion interactions, Synth. Met. 55-57 (1993) 1388

[24] C. Lopez, M.F. Mendes Viegas, G. Bidan, E. Vieil, Comparison of ion exchange properties of polypyrrole with and without immobilized dopants by optical beam deflection, Synth. Met. 63 (1) (1994) 73-78.

[25] T. -Hai Le, Y. Kim, H. Yoon, Electrical and electrochemical properties of conducting polymers, Polymer 9 (2017) 150-181.

[26] R.M. Latonen, M.N. Akieh, K. Vavra, J. Bobacka, A. Ivaska, Ion exchange behaviour of polypyrrole doped with large anions in electrolytes containing mono- and divalent metal ions, Electroanalysis 25 (2013) 991-1004. 